\section{MYRMECOPHILY IN THE COMMON PIERROT, CASTALIUS ROSIMON FABRICIUS (LEPIDOPTERA: LYCAENIDAE)}

\author{
Vinayan P. Nair \\ Department of Zoology, St. Joseph's College, Devagiri, Kozhikode, \\ Kerala 673008, India. \\ Email:vinayanpnair@yahoo.co.in
}

A great proportion of species in the butterfly family Lycaenidae are associated with ants, at least during a part of their larval development. Such interactions are termed Myrmecophily. Typically, myrmecophilous lycaenid caterpillars feed on plants and, at least in later instars, they produce energy-rich secretions from specialized exocrine glands (myrmecophilous organs). Ants visit caterpillars on the host plants and harvest these secretions. In return, ants protect the caterpillars from parasitoids and small insect predators.

While working on the butterflies of Government College Campus, Madappally, Kozhikode District, Kerala, I came across a Zizyphus sp., on which I saw two greenish lycaenid caterpillars, which were attended by some ants. Two different species of ants were regularly attending the larvae but they were not permanently attending them or attached with them. Observations were regularly carried out and towards the pupating stages were collected and kept under laboratory conditions.

One day it was found that a dipteran larva emerged out from one of the butterfly pupa and it pupated immediately. After some days from the other butterfly pupa Common Pierrot, Castalius rosimon emerged. The host plant was identified as Zizyphus oenoplia Linnaeus (Rhamnaceae). After some days an unknown dipteran parasitoid emerged from the dipteran pupa. The two ant species attending on the lycaenid larvae were identified as Crematogaster subnuda Mayr (Myrmicinae) and Anoplolepis gracilipes Smith (Formicinae).

Fiedler (1991) classified this butterfly as a moderately myrmecophilous type (ant association regularly occurs at least with part of the larvae). Hinton (as quoted by Fiedler, 1991) reported that the only ant species associated with Common Pierrot larvae was Prenolepis sp. Kunte (2000) also reported the same. The present observations are new records of ant species associated with Common Pierrot larvae. The only reported host plants of these butterflies are Zizyphus mauritania and Zizyphus rugosa (Wynter- Blyth, 1957). Gunathilagaraj et al. (1996) have reported introduced tree Acacia mellifera as a host plant of Castalius rosimon. Zizyphus oenoplia reported in this study is a new record for Common Pierrot.

\section{Acknowledgement}

I thank Prof. Dr. Konrad Fiedler, University of Bayreuth, Germany for providing literature on Lycaenidae. I am grateful to Dr. K.A. Karmaly (Research Scholar, Department of Zoology, University of Calicut) for identifying the ants and to Prof. Dr. T.C. Narendran, University of Calicut for encouragement.

\section{References}

Fielder, K. (1991). Systematic evolutionary and ecological implications of Myrmecophily within the Lycaenidae (Insecta: Lepidoptera: Papilionoidea). Bonner Zoologische Monographien 31: 1-210.

Gunathilagaraj, G., M. Ganeshkumar and P.T. Ramesh (1996). Butterflies of Coimbatore. Zoos' Print 12(1): 26-27.

Kunte, K. (2000). Butterflies of Peninsular India. Universities Press, Hyderabad.

Wynter-Blyth, M.A. (1957). Butterflies of the Indian Region. Bombay Natural History Society, Bombay. 